\title{
Response to "Corroboration of the Dentures Anecdote Involving Veridical Perception in a Near-Death Experience"
}

\author{
Gerald M. Woerlee, M.B.B.S, F.R.C.A. \\ Leiden and Leiderdorp, The Netherlands
}

\begin{abstract}
$A B S T R A C T$ : In this article, I address some of what I consider the inaccuracies and false assumptions in a recent article in this Journal entitled "Corroboration of the Dentures Anecdote Involving Veridical Perception in a Near-Death Experience" (Smit, 2008). I provide a medical explanation of how it was possible for the man reporting this remarkable NDE to have survived his period of cardiac arrest and how it was possible for him to have undergone an NDE. More importantly, I discuss how it was possible for this man to have undergone the truly unusual perceptions of feeling pain in his chest due to cardiac massage at the same time as his consciousness was displaced out of his body during an outof-body experience.
\end{abstract}

KEY WORDS: near-death experience, out-of-body experience, resuscitation, veridical perception, dentures

An article by Rudolf Smit (2008) in this Journal, entitled "Corroboration of the Dentures Anecdote Involving Veridical Perception in a Near-Death Experience," was an extensive discussion of a wellknown veridical NDE. This is an important NDE, because it is one in which an extensive interview with the head male nurse (TG) present during the resuscitation of "the man with the dentures" was recently published (Rivas, 2008), supplementing the information in the article by Smit (2008) and another by the male nurse (TG, 2008). These publications make a detailed analysis of this remarkable story possible.

Gerald M. Woerlee, M.B.B.S. (West Australia), F.R.C.A. (London), is an anesthesiologist affiliated with the Rijnland Hospital, Leiderdorp, The Netherlands, as well as an associate professor of anesthesiology at the Leiden University Medical Centre, Leiden, The Netherlands. Reprint requests should be addressed to Dr. G. M. Woerlee, Kagerstraat 4, 2334CR Leiden, The Netherlands; e-mail: gerry@woerlee.org. 
Professor Christopher French (2001) and I first learned of the dentures anecdote in the Lancet article published by Pim van Lommel and his co-workers in 2001 (van Lommel, van Wees, Meyers, \& Elfferich, 2001). Their article contained only a very summary account with no indication of the year in which the event took place, where it took place, as well as many other details. This was the only information French (2001) and I (Woerlee, 2004) had on which to base our explanations of this report. As regards my explanation, I made it using the assumption of standard medical practice in Dutch hospitals during the period 1990 to 2000 (Woerlee, 2004), as well as from my personal experience as an anesthesiologist, resuscitating cardiac arrest patients in The Netherlands since 1980. In his Lancet editorial, French (2001) made a very relevant comment about the corroborating evidence for reports as superficially wondrous as that of "the man with the dentures:" "On many previous occasions such attempts at corroboration have revealed that the evidence was not as impressive as it initially seemed" (French, 2001).

Unfortunately, the superficially extensive account in the article by Smit (2008) does no more than reinforce the hopes of those desperately searching for proof of a consciousness that is somehow immaterial, separable, and independent of the human body. Titus Rivas, a Dutch parapsychologist, recently published an extensive transcript of an exhaustive interview with the head male nurse named by his initials TG, who was present at the resuscitation of the patient called Mr. B. (Rivas, 2008). Subsequently, TG himself supplemented this transcript (TG, 2008). All this material provides sufficient information to explain this patient's story. So what are the basic medical facts supplementing the incomplete story given in Smit's (2008) article?

On a cold day at the end of 1979, a passerby discovered Mr. B. lying apparently unconscious in a field near the village of Ooij in the region of the city of Nijmegen, The Netherlands, and called an ambulance. The ambulance personnel found an ice-cold, unconscious, 44-year-old man and began cardiopulmonary resuscitation (CPR). During the CPR, they attached electrocardiogram (EKG) electrodes and found he was in a deadly heart rhythm called ventricular fibrillation. During ventricular fibrillation, the whole heart twitches uncontrollably and does not pump any blood around the body. At normal body temperatures, failure of the pumping action of the heart due to ventricular fibrillation causes loss of consciousness within 20 seconds, brain damage starts to develop after four minutes, and death is inevitable after 12 minutes. Accordingly, the ambulance personnel administered a 
powerful electrical shock (defibrillation) to try and convert the heart rhythm to a reasonably normal rhythm. They were unsuccessful, and still continuing CPR, they transported Mr. B. to the resuscitation room of the cardiology unit of the Canisius Hospital in Nijmegen.

TG noted when he first saw Mr. B. in the resuscitation room of the hospital: that Mr. B. had corpse-like blue and blotchy skin, as well as the wide open nonreactive pupils, blue nails, and lips typical of a person with severe oxygen starvation; was ice-cold to the touch; was unconscious and did not react to anything; and was still in ventricular fibrillation. The medical team rapidly placed him under a mechanical heart massage device that performed the work of cardiac massage for them-most likely the "Thumper," a mechanical heart massage device made and sold by Michigan Instruments since the 1970s. CPR was continued with the aid of this device, during which the team administered various drugs and regularly administered electrical shocks to Mr. B.'s chest to convert his heart rhythm from ventricular fibrillation to a rhythm that pumped blood. Mr. B. had dentures, and these were removed and placed upon a wooden shelf of the "crash cart" before continuing artificial respiration as part of the CPR.

Mr. B. remained totally unresponsive, unconscious, and unmoving during the resuscitation, during which TG regularly looked in his eyes to check the sizes of his pupils-a measure of brain oxygen starvation. TG was assisted by two female student nurses. The treating physicians and TG continually communicated with each other and, at one point, debated whether to continue the resuscitation. Finally, after about 90 minutes, they succeeded in establishing a reasonably normal heart rhythm, and Mr. B. was transferred to the intensive care unit while still apparently unconscious and requiring mechanical respiration.

After several days in the intensive unit during which he regained both the ability to breathe and consciousness, Mr. B. was transferred to the cardiology ward. One day he saw and recognized TG as the nurse who had removed his dentures during his cardiac resuscitation. During his interview with Rivas (2008), TG remarked that his own voice had a unique tone and was easily recognizable, a fact that Rivas confirmed. On the cardiology ward, TG spoke with the patient who informed TG that he had an out-of-body experience (OBE) shortly after admission to the resuscitation room. During this OBE, he saw the room from a vantage point outside his body, saw TG removing his dentures and placing them on a shelf, saw two female nurses whom he could not describe, saw the medical team resuscitating him, heard 
them discussing whether to cease resuscitation, and even tried telling them to continue. Most surprising of all, he told of feeling severe chest pain from the cardiac massage machine at the same time as his consciousness observed all this activity happening from a vantage point outside his body.

Mr. B. was finally discharged from the hospital without any evident neurological damage. The final diagnosis was that Mr. B. had suffered a massive myocardial infarction (heart attack), which was why he fell down while walking in the field near his home village of Ooij.

TG was adamant in all interviews that Mr. B. had all the signs of "clinical death," which is why he was certain that Mr. B. could not have seen him to recognize him, could not have observed him removing the dentures, and was not in a position or condition to have seen the room as he described it (Rivas, 2008; Smit, 2008; TG, 2008). In my original response (Woerlee, 2004), I provided medical explanations for these events. Smit (2008) called my explanation of these observations "conjectures" (p. 52). However, a cursory perusal of the facts presented in the summary of the story of the reports of Rivas (2008), supplemented by the extra information provided by TG (2008), immediately reveal sound medical explanations for these facts based upon the functioning of the human body-explanations proven by extensive clinical experience and human research. These explanations reveal the observations made by TG to be correct, but his interpretation to be conjecture, because of failure to recognize the effects of low body temperature (hypothermia) on the clinical picture of Mr. B.

The pain of Mr. B.'s myocardial infarct, possibly followed by a short period of abnormal heart rhythm, caused Mr. B. to faint or fall in the field where he was found. Incapacitated by a malfunctioning heart, he remained where he lay, cooled down, and lost consciousness. It was in this condition that a passerby discovered him lying in the field. Readers should remember that in 1979 there were no mobile telephones (cell phones). This means that the only option for the passerby was to find and use a public telephone booth or a telephone in a nearby house. Accordingly, several minutes were needed to call the ambulance.

The distance between the village of Ooij and the ambulance posts in the hospitals in Nijmegen is 10-12 km (6-7.2 miles). At maximum speed on the roads in 1979, it would have taken about six minutes for the ambulance to drive from Nijmegen to Ooij. The ambulance personnel then had to walk from the ambulance to the man and assess the situation. Assuming all things went smoothly after being called, the ambulance personnel would not have been on the scene for at least 11 
minutes. But no one saw this man fall down. The transcript tells only that the passerby saw this man lying in the field. Accordingly this man lay in the field for an uncertain period of time before discovery, after which his discoverer had to find a telephone and call the ambulance. So this man must have lain there for a time significantly longer than 11 minutes. Normal body temperature is 37 degrees Celsius. Since the 1960's, extensive medical experience has been acquired of the neurological consequences of cardiac operations performed upon people subjected to respiratory and cardiac arrest during the period of operation. This medical experience reveals that neurological damage occurs after 6-8 minutes of cardiac arrest at 28-32 degrees Celsius and after 30-60 minutes of cardiac arrest at 10-20 degrees Celsius (Sealy, 1989). Mr. B. was discharged from hospital without any neurological damage, so he could not have been in ventricular fibrillation between collapse and the arrival of the ambulance. After all, no blood is pumped around the body during ventricular fibrillation. Moreover, his body temperature would have been normal when he was walking on the field. So he collapsed in the field with a normal body temperature. This means he would have developed increasingly severe neurological damage after 3-5 minutes of ventricular fibrillation, a period far too short for any significant body cooling to have occurred. So he must have had a low normal heartbeat and circulation during the period between collapse and the arrival of the ambulance; otherwise he simply would not have survived this period without developing severe brain damage.

Clinical experience with people whose bodies cool to low temperatures, such as in the case of this man, shows they can retain consciousness and a normal heart rhythm, even at body temperatures as low as 21 degrees Celsius (Moser, Voelckel, Gardetto, Sumann, \& Wenzel, 2005; Oberhammer, Beikircher, Hormann, Lorenz, AdlerKastner, \& Brugger, 2008). Paradoxically, it is the movements and ministrations of the rescuers that disturb the fragile balance of a hypothermic person's heart function to induce ventricular fibrillation (Moser et al., 2005; Oberhammer et al., 2008; Steedman, Rainer, \& Campanella, 1997). So it was the efforts of the ambulance personnel to resuscitate this man that most likely induced the ventricular fibrillation subsequently observed. His hypothermic body was able to survive prolonged periods of little if any blood flow, because a hypothermic body consumes less oxygen than a normally warm body. After all, as everyone knows, cold meat stays fresh longer than warm meat. The same is true of the human body. 
TG was correct when he said wide nonreactive pupils are a sign of brain oxygen starvation (Huet, Karliczek, \& Coad, 1989; Steen-Hansen, Hansen, Vaagenes, \& Schreiner, 1988), but hypothermia renders the value of this clinical sign uncertain (Mallet, 2002; Steedman et al., 1997). Furthermore, extensive experience with resuscitation of hypothermic persons reveals that a hypothermic person may appear dead to an observer because of reduced movements, wide open nonreactive pupils, blotchy corpse-like appearance, and ice-coldness to the touch. Thus, the signs of clinical death such as absence of breathing, absence of heartbeat, and wide open, nonreactive pupils are not accurate determinants of the actual clinical condition in hypothermic patients (Mallet, 2002; Moser et al., 2005; Oberhammer et al., 2008). Moreover, clinical practice shows that hypothermic people can survive prolonged periods of cardiac arrest without severe neurological damage (Mallet, 2002; Moser et al., 2005; Oberhammer et al., 2008). In fact, it is standard medical practice in emergency rooms to resuscitate hypothermic patients until they are warm before declaring them dead (American Heart Association [AHA], 2005b). This is the origin of the emergency room physician's adage regarding hypothermic patients: "You're not dead until you're warm and dead." So the remarks of TG about the clinical condition of Mr. B. were correct for people with a normal body temperature but were incorrect in the case of this hypothermic man.

Turning now to the subject of Mr. B.'s level of consciousness, clinical experience with hypothermic persons shows that consciousness can be maintained down to body temperatures as low as 21 degrees Celsius (Mallet, 2002; Moser et al., 2005; Oberhammer et al., 2008). Mr. B. was subjected to almost continual cardiac massage, initially by hand and later by means of a special machine in the resuscitation room of the hospital. Human research demonstrates that manual external cardiac massage is less effective in generating a flow of blood around the body than external machine cardiac massage with a "Thumper," which in turn is less effective than internal cardiac massage (AHA, 2005a). Reports of experiences with these three forms of cardiac massage applied to cardiac arrest patients show that some people do regain consciousness during cardiac massage for cardiac arrest applied by hand (Bihari \& Rajajee, 2008), by means of a "Thumper" (Lewinter, Carden, Nowak, Enriquez, \& Martin, 1989), as well as by internal cardiac massage (Miller, Davie, \& Douglas, 1961). TG himself remarked that cardiac massage with the cardiac massage machine as used in the Canisius Hospital at that time was 
sometimes so effective that some people regained consciousness, even though they had no heartbeat at the time (TG, 2008).

In other words, TG was saying that regaining conscious was possible and actually occurred during cardiac massage for cardiac arrest with this machine. External cardiac massage applied by hand or machine generates sufficient blood flow around the body (cardiac output) to sustain consciousness in about $20 \%$ of people undergoing cardiac massage for cardiac arrest (Woerlee, 2008, pp. 279-294). However such consciousness need not manifest as obvious movements or speech, because people undergoing cardiac massage for cardiac arrest are suffering from the effects of brain oxygen starvation. Brain oxygen starvation at a certain level does not cause loss of consciousness, but it does cause total paralysis of all movements during which people appear unconscious even though they are conscious (Rossen, Kabat, $\&$ Anderson, 1943). The mechanism of this apparent unconsciousness is presumably the same as that of the "locked-in" syndrome in which oxygen starvation of parts of the brainstem causes those affected to be totally paralyzed and appear unconscious even though they are conscious (Laureys et al., 2005).

Another piece of evidence for the likelihood that Mr. B. was conscious was the fact that he felt extreme pain in his chest due to the cardiac massage, even though he had no heartbeat at the time. There is even a known report of a person who regained consciousness during cardiac massage and who, in the absence of a heartbeat, required powerful painkilling medication to treat the pain of the cardiac massage (Lewinter et al., 1989). All these factors indicate that Mr. B. was conscious as a result of cardiac massage but was paralyzed due to the effects of oxygen starvation and hypothermia.

Because Mr. B. was conscious, he could hear what was being said and could feel the cardiac massage. This also means Mr. B. could feel his dentures being removed, hear them being laid upon a wooden surface, feel the shocks of the defibrillator, feel the mask and the artificial respiration, hear the voices of two female student nurses, hear the unique voice of TG, hear the medical team discussing whether to stop the resuscitation, and hear the sounds in the room including the sounds of ampoules and instruments. He also saw the face of TG who regularly looked into his eyes to check the sizes of his pupils. All these sensations enabled him to construct in his mind an image of the events of his resuscitation. Blind people do the same: They can give very good descriptions of the events in their vicinity as well as their surroundings (see extensive discussion in Woerlee, 2008, 
pp. 114-117). This was how it was possible for this man to give such a good description of his surroundings and the events during his resuscitation. Moreover, after recovering normal consciousness, he was able to blend his perceptions into a coherent story.

How, though, do these factors explain his OBE? An OBE is not at all surprising in this situation, because human medical research has established that brain oxygen starvation induces abnormal sensations of body position due to its effects upon the brain (Horak, Nashner, \& Diener, 1990, p. 306, in Van Liere \& Stickney, 1963) and can even induce OBEs (Brugger, Regard, Landis, Oelz, 1999; Woerlee, 2009). Mr. B. felt the pain from the cardiac massage at the same time as he underwent an OBE, so it is clear that his consciousness was located inside his body. Aside from an extensive literature demonstrating that the OBE is a product of the functioning of the body, the most compelling evidence for the reality that the OBE is a product of bodily function is given by people describing their OBEs. They describe their consciousness as somehow separated from their physical bodies, reporting that this consciousness is able to pass through the human body in which it was housed, as well as through walls, windows, and roofs, without any apparent resistance. Moreover this consciousness is unseen, unheard, and cannot be sensed with any human sense or apparatus known to humankind. This common observation means that the separated consciousness has no interaction with physical matter or physical forces. This observation means that it is impossible for the separated consciousness during an OBE to hear sounds (see extensive discussion in Woerlee, 2008, pp. 264-66) or to see with light (see extensive discussion in Woerlee, 2008, pp. 120-123). These things mean the separated consciousness of a person is deaf to sound and blind to light. Yet people reporting their OBEs tell of hearing verifiable speech and/or seeing verifiable colors. So does the separated consciousness hear and see by means of paranormal abilities?

Unfortunately for many believers in paranormal abilities, the paranormal is an untenable hypothesis, because to invoke a paranormal explanation for the ability to hear with sound and to see with light would mean that the many millions of blind and deaf people now alive, and the many more that have lived in the past, would be more gifted with paranormal powers than people who are not so handicapped (see Woerlee, 2008, pp. 87-88). The only way to answer this problem is to conclude that the consciousness of people undergoing an OBE is firmly based within the physical brains of these people. Accordingly, a person undergoing an OBE perceives events in the vicinity of the 
physical body with the physical senses of the body, and these perceptions are coupled to a sensation of displacement outside the body as well as an autoscopic hallucination of the body. The person subsequently remembers the totality of this experience and integrates it into the wondrous imagery of the OBE. This explains all the perceptions of the OBE of Mr. B.

In conclusion, it may be said that this report of "the man with the dentures" is similar in many ways to the veridical Pam Reynolds story as first published by Michael Sabom (1998), because careful analysis of the facts in the story strips away all fantastical and wondrous explanations to reveal the ways the human body generates the apparently wondrous sensations of the NDE and OBE (Woerlee, 2008, pp. 256-271). Consequently, Smit was more correct than he realized in the conclusion of his article:

The main purpose of this article was to set the record straight as to the facts of this case, while admitting that this case cannot constitute definitive proof of continuation of consciousness, let alone survival of death. But it does provide corroborating testimony that something extraordinary happened at the time, an event that should not be dismissed out of hand as a ridiculous story made up by naive believers. (Smit, 2008, p. 61)

Indeed, this was a remarkable story, but it is not a story providing evidence for the survival of consciousness after death, nor is it a story providing evidence for a separable and independent human consciousness. Instead, it is a report revealing much about how the functioning of the human body generates the remarkable sensations of the OBE and the NDE.

\section{References}

American Heart Association. (2005a). Part 6: CPR techniques and devices. Circulation, 112, IV-47-IV-50.

American Heart Association. (2005b). Part 10.4: Hypothermia. Circulation, 112, IV-136-IV-138.

Bihari, S., \& Rajajee, V. (2008). Prolonged retention of awareness during cardiopulmonary resuscitation for asystolic cardiac arrest. Neurocritical Care, 9, 382-386.

Brugger, P., Regard, M., Landis, T., \& Oelz, O. (1999). Hallucinatory experiences in extreme-altitude climbers. Neuropsychiatry, Neuropsychology, and Behavioral Neurology, 12, 67-71.

French, C. C. (2001). Dying to know the truth: Visions of a dying brain, or false memories? Lancet, 358, 2010-2011.

Horak, F. B., Nashner, L. M., \& Diener, H. C. (1990). Postural strategies associ- 
ated with somatosensory and postural loss. Experimental Brain Research, 82, 167-177.

Huet, R. C. G. G., Karliczek, G. F., \& Coad, N. R. (1989). Pupil size and light reactivity in hypothermic infants and adults. Intensive Care Medicine, 15, 216-217.

Laureys, S., Pellas, F., Van Eeckhout, P., Ghorbel, S., Schnakers, C., Perrin, F., .. . Goldman, S. (2005). The locked-in syndrome: What is it like to be conscious but paralyzed and voiceless? Progress in Brain Research, 150, 495-512.

Lewinter, J. R., Carden, D. L., Nowak, R. M., Enriquez, E., \& Martin, G. B. (1989). CPR dependent consciousness: Evidence for cardiac compression causing forward flow. Annals of Emergency Medicine, 18, 1111-1115.

Mallet, M. L. (2002). Pathphysiology of accidental hypothermia. Quarterly Journal of Medicine, 95, 775-785.

Miller, J. B., Davie, R. D. M., \& Douglas, D. M. (1961). The efficiency of cardiac massage in ventricular fibrillation. Description of an instance of recovery of consciousness without spontaneous heartbeat. British Journal of Anaesthesia, $33,22-23$.

Moser, B., Voelckel, W., Gardetto, A., Sumann, G., \& Wenzel, V. (2005). One night in a snowbank: A case report of severe hypothermia and cardiac arrest. Resuscitation, 65, 365-368.

Oberhammer, R., Beikircher, W., Hormann, C., Lorenz, I., Adler-Kastner, L., \& Brugger, H. (2008). Full recovery of an avalanche victim with profound hypothermia and prolonged cardiac arrest treated by extracorporeal re-warming. Resuscitation, 76, 474-480.

Rivas, T. (2008). Een gesprek met TG over de man met het Gebit [A conversation with TG about the man with the dentures]. Terugkeer, 19(3), 12-20.

Rossen, R., Kabat, H., \& Anderson, J. P. (1943), Acute arrest of cerebral circulation in man. Archives of Neurology and Psychiatry, 50, 510-528.

Sabom, M. (1998). Light and death. Grand Rapids, MI: Zondervan.

Sealy, W. C. (1989), Hypothermia: Its possible role in cardiac surgery. Annals of Thoracic Surgery, 47, 788-791.

Smit, R. H. (2008). Corroboration of the dentures anecdote involving veridical perception in a near-death experience. Journal of Near-Death Studies, 27, $47-61$.

Steedman, D. J., Rainer, T., \& Campanella, C. (1997). Cardiopulmonary resuscitation following profound immersion hypothermia. Journal of Accident and Emergency Medicine, 14, 170-172.

Steen-Hansen, J. E., Hansen, N. N., Vaagenes, P., \& Schreiner, B. (1988). Pupil size and light reactivity during cardiopulmonary resuscitation: A clinical study. Critical Care Medicine, 16, 69-70.

TG. (2008). Commentaar op Woerlee door A-verpleegkundige TG [Commentary on Woerlee by a registered nurse TG]. Terugkeer, 19(4), 8.

Van Liere, E. J., \& Stickney, J. C. (1963). Hypoxia. Chicago, IL: University of Chicago Press.

van Lommel, P., van Wees, R., Meyers, V., \& Elfferich, I. (2001). Near-death experiences in survivors of cardiac arrest: A prospective study in the Netherlands. Lancet, 358, 2039-2045. 
Woerlee, G. M. (2004). Cardiac arrest and near-death experiences. Journal of Near-Death Studies, 22, 235-249.

Woerlee, G. M. (2008). The unholy legacy of Abraham. Retrieved from www. unholylegacy.woerlee.org

Woerlee, G. M. (2009). Anesthesia \& hypoxia. Retrieved from http://anesthesiaweb. org/hypoxia.php 